\title{
Analisa Biaya Dan Penjadwalan Pada Proyek Penataan Bangunan Kawasan Strategis Masjid Raya Sumbar Kota Padang
}

Nasrul .MT, Wilda Yurman

Email : nasrullen@gmail.com

\begin{abstract}
Abstrak: Dalam pelaksanaan Proyek Penataan Bangunan Kawasan Strategis Masjid Raya Sumbar Kota Padang dikerjakan dengan perencanaan yang matang agar proyek selesai sesuai dengan jangka waktu yang telah ditentukan.

Pada kenyataannya proyek selalu mendapat kendala sehingga proyek tersebut tidak berlangsung sesuai rencana.Oleh sebab itu kita dituntut untuk dapat mengendalikan biaya dan penjadwalan agar pelaksanaan proyek berjalan sesuai yang direncanakan.

Banyak kendala dilapangan mengakibatkan keterlambatan pekerjaan dilapangan.Dalam dokumen kontrak diberi sanksi dengan ketentuam 1/1000 dari harga kontrak (sebelum ppn), mengacu ke pada permen PUPR Nomor 31/PRT/M/2015 lampiran I standar dan pedoman pengadaan Pekerjaan konstruksi tunggal SSUK pasal 66.4 huruf c.

Dan menerapakan metode CPM dalam penjadwalan kembali proyek penataan bangunan kawasan strategis masjid raya sumbar kota padang dengan mengunakan metode CPM diperoleh waktu pelaksanaan pekerjaan 203 hari untuk menyelesaikan. Sedangkan penjadwalan yang direncanakan oleh pihak pelaksana pekerjaan 210 Hari.
\end{abstract}

\section{PENDAHULUAN}

\subsection{Latar Belakang}

Masjid Raya Provinsi Sumatera Barat memiliki luas tanah $40.343 \mathrm{~m}^{2}$, luas bangunan utama Masjid ini $4.430 \mathrm{~m}^{2}$. Hal tersebut menjelaskan bahwa masih ada tersisa lahan kosong yang dapat dimanfaatkan untuk menunjang efesiensi Masjid Raya Sumatera Barat.

Kemudian melalui Direktorat Jenderal Cipta Karya Kementerian Pekerjaan Umum dan Perumahan Rakyat melalui Direktorat Bina Penataan Bangunan, sesuai dengan surat $\mathrm{Pj}$. Gubernur Sumatera Barat Nomor : 690/2482Sekre/PJTRP-2015 Tanggal 17 Agustus 2015 Perihal : Usulan Penataan Kawasan Masjid Raya Sumatera Barat, telah memfasilitasi penataan kawasan Masjid Raya Sumatera Barat berupa DED Kawasan Masjid Raya yang dilaksanakan pada tahun 2015. Pada tahun 2016 -2017 akan dilaksanakan kegiatan fisik penataan Kawasan Masjid Raya Sumatera Barat.

Pada pengerjaan proyek konstruksi, diperlukan suatu manajemen yang tertata dengan baik dan sesuai dengan kebutuhan agar proyek tersebut berhasil dengan baik. Manajemen adalah merencanakan, mengorganisir, memimpin, dan mengendalikan sumber daya perusahaan untuk mencapai sasaran jangka pendek yang telah ditentukan. Sebagai patokan keberhasilan suatu proyek konstruksi adalah ditentukan oleh mutu, waktu yang ditetapkan dan biaya yang sesuai rencana.

Oleh karena itu, dalam pelaksanaan suatu proyek konstruksi selalu ada kemungkinan, bahwa waktu yang dibutuhkan untuk menyelesaikan proyek, akan melebihi waktu yang telah ditentukan dalam dokumen kontrak pekerjaan, dengan kata lain bahwa waktu penyelesaian proyek menjadi terhambat. Keterlambatanpekerjaankonstruksi akan menyebabkan kerugian baik moril maupun material.Pihak yang terkena dampak kerugian tersebut adalah pihak yang berhubungan langsung dengan proyek yaitu Kontraktor. Kontraktor akan mengalami kerugian waktu dan biaya, karena keuntungan yang diharapkan oleh Kontraktor berkurang, dan tidak mencapai target yang diharapkan bahkan tidak mendapat keuntungan sama sekali.

Selain itu, adanya keterlambatan berakibat kehilangan peluang pekerjaan proyek lain. Adapun bagi Owner, keterlambatan penyelesaian pekerjaan proyek akan menyebabkan kerugian terhadap waktu operasi hasil proyek, sehingga penggunaan hasil pembangunan proyek menjadi mundur atau terlambat.

Atas dasar di atas penulis ingin menganalisa pengendalian biaya dan penjadwalan pada proyek Penataan Bangunan Kawasan Strategis Masjid Raya Sumbar Kota Padang mengingat salah satu kriteria yang menjadi indikator dalam menentukan kelancaran 
dari pelaksanaan proyek adalahbiaya dan waktu. Selain itubiaya dan waktu.

Dalam pembahasan selanjutnya akan dianalisipengendalian biaya dan penjadwalan pada proyekberdasarkan koefisien-koefisien yang telah ditetapkan.

\subsection{Tujuan Penulisan}

Tujuan dari penulisan tugas akhir ini adalah sebagai berikut :

1. Apakah biaya pelaksanaan proyek sesuai dengan RAB.

2. Apakah jadwal pelaksanaan proyek sesuai dengan jadwal yang direncanakan.

\subsection{Batasan Masalah}

Untuk mencapai tujuan dalam penelitian ini, maka penelitian membatasi dengan ruang lingkup sebagai berikut :

1. Penelitian dilakukan pada Proyek Penataan Bangunan Kawasan Strategis Masjid Raya Sumbar Kota Padang

2. Keterlambatan proyek dilakukan pada masa pelaksanaan kontruksi.

3. Waktu pelaksanaan menerapkan metode CPM dalam penjadwalan kembali pada Proyek Penataan Bangunan Kawasan Strategis Masjid Raya Sumbar Kota Padang

4. Pengambilan data dilakukan dari Rencana Anggaran Biaya, laporan kemajuan fisik pekerjaan, dan time schedule.

\section{KAJIAN TEORI}

\subsection{Manajemen Konstruksi}

Manajemen Konstruksi (Construction

Management), adalah bagaimana agar sumber daya yang terlibat dalam proyek konstruksi dapat diaplikasikan oleh manajer proyek secara tepat. Sumber daya dalam proyek konstruksi dapat dikelompokkan menjadi manpower, material, machines, money, method. Dalam Manajemen Konstruksi banyak sekali pihak yang terlibat, baik secara langsung maupun tidak langsung. Hubungan antara pihak-pihak yang terlibat dalam suatu proyek dibedakan atas hubungan fungsional dan hubungan kerj (Ervianto, 2005).

\subsection{Indikator Kinerja Proyek}

\subsubsection{Indikator Kinerja Biaya}

Biaya pengelolaan proyek adalah hal vital yang harus dicermati pengendaliannya agar tidak terjadi kerugian-kerugian yang dapat membuat proyek terhenti atau mengalami keterlambatan karena tidak adanya pasokan keuangan untuk pembelian material, pembayaran sewa alat, pembayaran tenaga kerja serta operasional proyek. Untuk memantau keuangan proyek diperlukan arus kas proyek yang menunjukkan rencana aktual penggunaan biaya dalam periode waktu proyek.

\subsubsection{Bagan Balok}

Bagan Balok (Barchart) Dalam Bar Chart (Bagan Balok), kegiatan digambarkan dengan balok horizontal. Panjang balok menyatakan lama kegiatan dalam skala waktu yang dipilih. Bagan balok terdiri atas sumbu y yang menyatakan kegiatan atau paket kerja dari lingkup proyek dan digambarkan sebagai balok, sedangkan sumbu $\mathrm{x}$ menyatakan satuan waktu dalam hari, minggu, atau bulan sebagai durasinya.

\subsubsection{Pengendalian Progres Waktu Proyek dengan Kurva $S$}

Kurva $\mathrm{S}$ adalah alat monitoring evaluasi yang informatif, apalagi dengan tampilan kombinasi menggunakan diagram batang, sehingga pengelola proyek dapat dengan cepat mengantisifasi bila ada penyimpangan pada proyek.

Untuk mempermudah monitoring dan evaluasi diberika Baseline pada periode tertentu untuk memprediksi progres dimasa datang.Pengukuran kemajuan aktual pekerjaan yang sudah dilakukan dapat dipakai sebagai data input dalam pengendalian proyek. Caranya dengan menghitung volume pekerjaan masing masing kegiatan, lalu dibuatkan bobotnya dalam persentase kumulatif biaya dalam bentuk kurva S.

Kurva $\mathrm{S}$ juga didapat dari dari plot bobot kumulatif pekerjaan sebagai persentase dari biaya per-item pekerjaan dibagi dengan total anggaran proyek dengan data - data yang ada format laporan penegndalian Kurva $S$ sangat bermanfaat untuk dipakai sebagai laporan bulanan dan laporan kepada pemimpin proyek, karena kurva ini dapat dengan jelas menunjukan kemajuan proyek dalam bentuk yang mudah dipahami. 


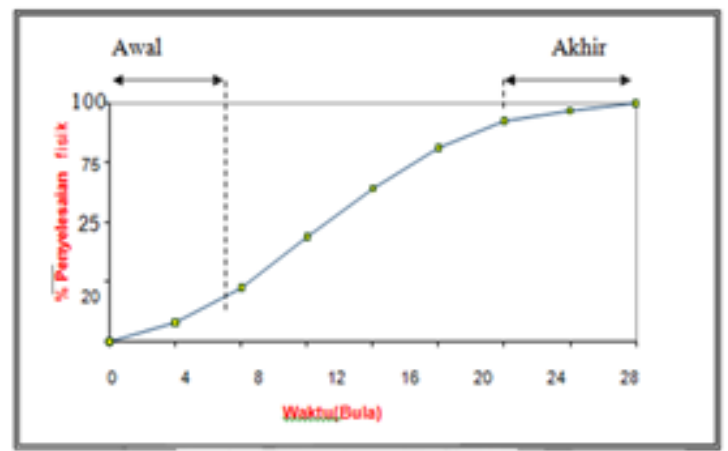

Gambar 2.1. Garfik "S"

Sumber : Imam Soeharto, 1995

\subsubsection{Metode CriticalPathMetod( CPM)}

Metode Jalur Kritis (Critical Path Method) Critical Path Method (CPM) merupakan dasar dari system perencanaan dan pengendalian kemajuan pekerjaan yang didasarkan pada network atau jaringan kerja. CPM pertama kali digunakan di inggris pada pertengahan tahun 50an pada suatu proyek pembangkit tenaga listrik, kemudian di dikembangkan oleh Intergrated Engineering Control Group of E.I du Pont de Nemours and Company yang diprakarsai oleh Walker dan Kelly jr. tahun 1957, keduanya dari Reningtone Rand, Univac Computer Division,Jurnal Sipil Statik Vol.4 No.9 September 2016 (551-558) ISSN: 2337-6732 553 yang di namakan Penjadwalan Jalur Kritis (Critical Path Schedulling-CPS) (Tarore2002)

\section{Jaringan Kerja}

Jaringan Kerja pada prinsipnya adalah hubungan ketergantungan antara bagian-bagian pekerjaan yang digambarkan atau divisualisasikan dalam diagram network. Dengan demikian dapat dikemukakan bagian-bagian pekerjaan yang harus didahulukan, sehingga dapat dijadikan dasar untuk melakukan pekerjaan selanjutnya dan dapat dilihat pula bahwa suatu pekerjaan belum dapat dimulai apabila kegiatan sebelumnya belum selesai dikerjakan.

Simbol-simbol yang digunakan dalam menggambarkan suatu network adalah sebagai berikut (Hayun, 2005) :

$\longrightarrow$ (anak panah/busur), mewakili sebuah kegiatan atau aktivitas yaitu tugas yang dibutuhkan oleh proyek. Kegiatan disini didefinisikan sebagai hal yang memerlukan duration (jangka waktu tertentu) dalam pemakaian sejumlah resources (sumber tenaga, peralatan, material, biaya). Kepala anak panah menunjukkan arah tiap kegiatan, yang menunjukkan bahwa suatu kegiatan dimulai pada permulaan dan berjalan maju sampai akhir dengan arah dari kiri ke kanan. Baik panjang maupun kemiringan anak panah ini sama sekali tidak mempunyai arti. Jadi, tak perlu menggunakan skala.<smiles>C1CCCCCC1</smiles>
Lingkaran $\mathrm{kecil} / \mathrm{simpul} /$ node), mewakił sebuah kejadian atau peristiwa atau event. Kejadian (event) didefinisikan sebagai ujung atau pertemuan dar isatu atau beberapa kegiatan. Sebuah kejadian mewakili satu titik dalam waktu yang menyatakan penyelesaian beberapa kegiatan dan awal beberapa kegiatan baru. Titik awal dan akhir dari sebuah kegiatan karena itu dijabarkan dengan dua kejadian yang biasanya dikenal sebagai kejadian kepala dan ekor. Kegiatan-kegiatan yang berawal dari saat kejadian tertentu tidak dapat dimulai sampai kegiatan-kegiatan yang berakhir pada kejadian yang sama diselesaikan. Suatu kejadian harus mendahulukan kegiatan yang keluar dari simpul/node tersebut.

- - - $\longrightarrow$ (anak panah terputusputus),menyatakan kegiatan semu atau dummy activity. Setiap anak panah memiliki peranan ganda dalam mewakili kegiatan dan membantu untuk menunjukkan hubungan utama antara berbagai kegiatan. Dummy disini berguna untuk membatasi mulainya kegiatan seperti halnya kegiatan biasa, panjang dan kemiringan dummy ini juga tak berarti apa-apasehingga tidak perlu berskala. Bedanya dengan kegiatan biasa ialah bahwa kegiatan dummy tidak memakan waktu dan sumbar daya, jadi waktu kegiatan dan biaya sama dengan nol.

kegiatan pada lintasan kritis. Dalam penggunaannya, simbol-simbol ini digunakan dengan mengikuti aturan-aturan sebagai berikut (Hayun,

2005) :

a. Di antara dua kejadian (event) yang sama, hanya boleh digambarkan satu anak panah.

b. Nama suatu aktivitas dinyatakan dengan huruf atau dengan nomor kejadian.

c. Aktivitas harus mengalir dari kejadian bernomor rendah ke kejadian bernomor tinggi.

d. Diagram hanya memiliki sebuah saat paling cepat dimulainya kejadian (initial event) dan 
sebuah saat paling cepat diselesaikannya kejadian (terminal event).

Ervianto (2004) menjelaskan dalam CPM (Critical Path Method) dikenal EET ( Earliest Event Time) dan LET (Last Event Time), Total Float, Free Float, dan Float Interferen, EET itu sendiri adalah peristiwa paling awal atau waktu tercepat dari event. LET adalah peristiwa paling akhir atau waktu paling lambat dari event.

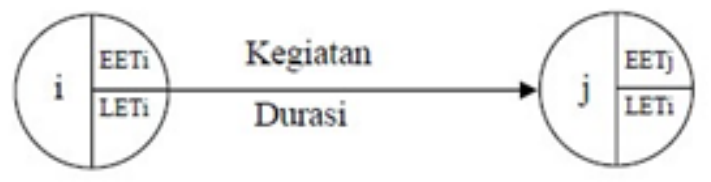

Gambar2.1 EETdanLETsuatuKegiatan

\subsection{Keterlambatan Proyek Konstruksi}

Menurut Soeharto (1995) Pelaksanaan proyek yang tidak sesuai rencana, dapat mengakibatkan keterlambatan proyek. Pada pelaksanaan proyek kontruksi, keterlambatan proyek sering kali terjadi, yang dapat menyebabkan berbagai bentuk kerugian bagi penyedia jasa dan pengguna jasa. Bagi kontraktor, keterlambatan selain dapat menyebabkan pembengkakan biaya proyek akibat bertambahnya waktu pelaksanaan proyek, dapat pula mengakibatkan menurunannya kredibilitas kontraktor untuk waktu yang akan datang. Sedangkan bagi pemilik, keterlambatan penggunaan atau pengoperasian hasil proyek kontruksi dan seringkali berpotensi menyebabkan timbulnya perselisihan dan klain antara pemilik dan kontraktor.

\subsubsection{Jenis - Jenis Keterlambatan}

Kraim dan dicman yang dikutip dari wahyudi (2006) menyatakan keterlamatan dapat dibagi menjadi tiga jenis utama, yaitu :

1. Keterlambatan yang tidak dapat dimaafkan (Non Excusable Delays)

Non Excusable Delays adalah keterlambatan yang diakibatkan oleh tindakan, kelalaian, atau kesalahan kontraktor.

2. Keterlambatan yang dapat dimaafkan (Excusesable Delays)

Excusesable Delays adalah keterlambatan yang disebabkan oleh kejadian-kejadian diluar kendali baik pemilik maupun kontraktor. Pada bagian ini kontraktor dapat kompensasi berupa perpanjangan waktu.

3. Keterlambatan yang layak mendapat ganti rugi (Conpensable Delays)

Conpensable Delays adalah keterlambatan yang diakibatkan oleh tindakan, kelalaian atau kesalahan pemilik. Pada kejadian ini, kontraktor biasanya mendapat kompensasi berupa perpanjangan waktu dan tambahan biaya operasional yang perlu selama keterlambatan pelaksanaan tersebut.

\subsubsection{Literatur Penyelesaian Proyek (Solusi)}

Adapun solusi untuk penyelesaian pekerjaan adalah :

1. Menjaga kedisiplinan tim proyek

2. Melakukan rapat harian

3. Aktif menggali informasi

4. Selalu memberikan informasi

5. Melakukan update yang rutin atas pekerjaan

6. Menambah jam kerja

7. Menambah personil proyek

8. Menjaga kualitas pekerjaan

9. Memastikan ketersediaan dana dan mengusahakan dana pendamping

10. Menempatkan personil khusus yang memonitoring proses dan dokumen administrasi.

\subsection{Metode Pengumpulan Data}

Jenis data yang digunakan dalam penelitian ini adalah data sekunder. Data sekunder adalah data yang lebih dulu dikumpulkan dan dilaporkan oleh orang atau instansi di luar diri sendiri. Datadata yang dibutuhkan dalam penelitian ini adalah:

1. $\mathrm{RAB}$

2. Time Schedule

3. Laporan Mingguan dan Bulanan

Data tersebut diperoleh langsung dari lokasi proyek.

\subsection{Data Proyek}

Untuk mendapatkan informasi yang lebih detail mengenai Proyek Penataan Bangunan Kawasan Strategis Masjid Raya Sumbar Kota Padang dijelaskan data-data proyek sebagai berikut :

\section{Data Umum:}

Satuan Kerja : Penataan Bangunan dan Lingkungan Provinsi Sumatera Bart

Nama Pekerjaan : Penataan Bangunan Kawasan Strategis Masjid Raya Sumbar Kota Padang

$230 \quad$ Fakultas Teknik UMSB $\quad$ ISSN 2599-2081

EISSN 2599-2090 
Sumber Dana : APBN Tahun 2017

Lokasi Pekerjaan: Kota Padang

Data Proyek :

Nomor Kontrak :IK.02.04/Kont -

Fis/Pelaks.PBL - SB/39/V - 2017 Tanggal

23 Mei 2017

Nilai Kontrak : Rp 28.264.437.000,-

Nomor Kontrak Addendum II : 39/ADD-II/Kont-

Fis/Pelaks.PBL-SB/VIII-2017Tgl 27 November

2017

Nilai Kontrak : Rp 30.264.437.000,-

Masa Pelaksanaan: 210 (Seratus Enam Puluh Satu) Hari Kalender

Kontraktor : PT. BAHANA PRIMA NUSANTARA - KSO PT. NAGA SAKTI KONTRUKSI

Konsultan Pengawas : CV.ARCE

Ketentuan : Terhadap setiap hari keterlambatan penyelesaian pekerjaan penyedia akan dikenakan Denda Keterlambatan sebesar 1/1000 ( satu per seribu ) dari Nilai Kontrak atau bagian tertentu dari Nilai Kontrak sebelum PPN sesuai dengan Syarat-Syarat Umum Kontrak.

\subsection{Langkah - langkah Penelitian}

Analisi ssistematika pengendalian biaya dan waktu dapat dilihat pada gambar 3.1 berikut ini :

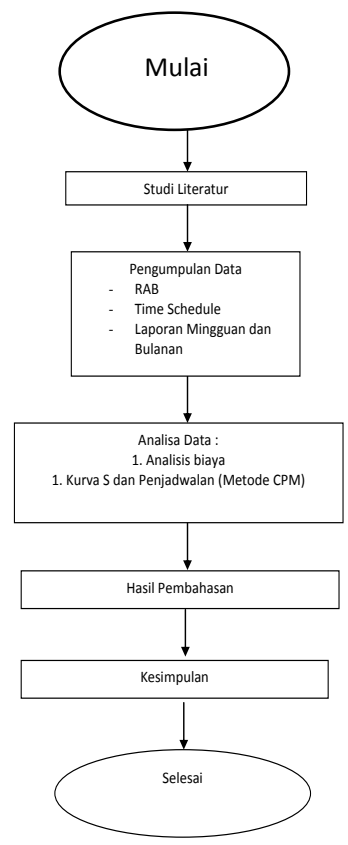

Gambar 3.1Langkah-langkah penelitian

\section{ANALISIS DAN PEMBAHASAN}

Pembangunan Penataan Bangunan Kawasan Strategis Masjid Raya Sumbar Kota Padang, pelaksanaannya dimulai dari Tanggal 23 Mei 2016 dan selesai pada akhir bulan Desember 2017 (sesuai dengan waktu rencana). Adapun beberapa data yang digunakan penulis untuk menganalisa pengendalian biaya pada pelaksanaan Pembangunan Penataan Bangunan Kawasan Strategis Masjid Raya Sumbar Kota Padangberikut :

1. Jadwal pelaksanaan pekerjaan

2. Daftar kuantitas dan harga (optimasi)

3. Laporan pelaksanaan pekerjaan mingguan

4. Laporan pelaksanaan pekerjaan bulanan

\subsection{Biaya Proyek}

Biaya proyek pembangunanan Jalan Batu Hampar - Sungai Betung Mudik

Dalam Rencana Anggaran Biaya adalah Rp. 28.264.437.000 (termasuk PPN 10\%), setelah dilakukan addendum kontrak pada tanggal 27 November 2017 maka nilai kontrak bertambah menjadi Rp. 30.264.437.000 (Termasuk PPN $10 \%)$.

\subsubsection{Perhitungan Bobot Pekerjaan}

Persentase Bobot Pekerjaan :

$\mathrm{PBP}=\frac{\text { Volume } \mathrm{x} \text { Harga Satuan }}{\text { Harga Bangunan }} \times 100 \%$

Adapun perhitungan persentase bobot pekerjaan pada setiap item pekerjaan dapat dilihat pada tabel di bawah ini

\subsubsection{Rencana Anggaran Biaya}

Rencana anggaran pelaksanaan adalah rencana pembiayaan yang dibuat oleh kontrak untuk menyelesaikan suatu pekerjaan dengan kondisi harga pada saat royek dimulai.

Tabel 4.1 Rekap nilai RAB kontrak, nilai RAB Addendum I dan nilai RAB Addendum II. 
Vol. I No.2 Juni 2018

http://joernal.umsb.ac.id/index.php/RANGTEKNIKJOURNAL

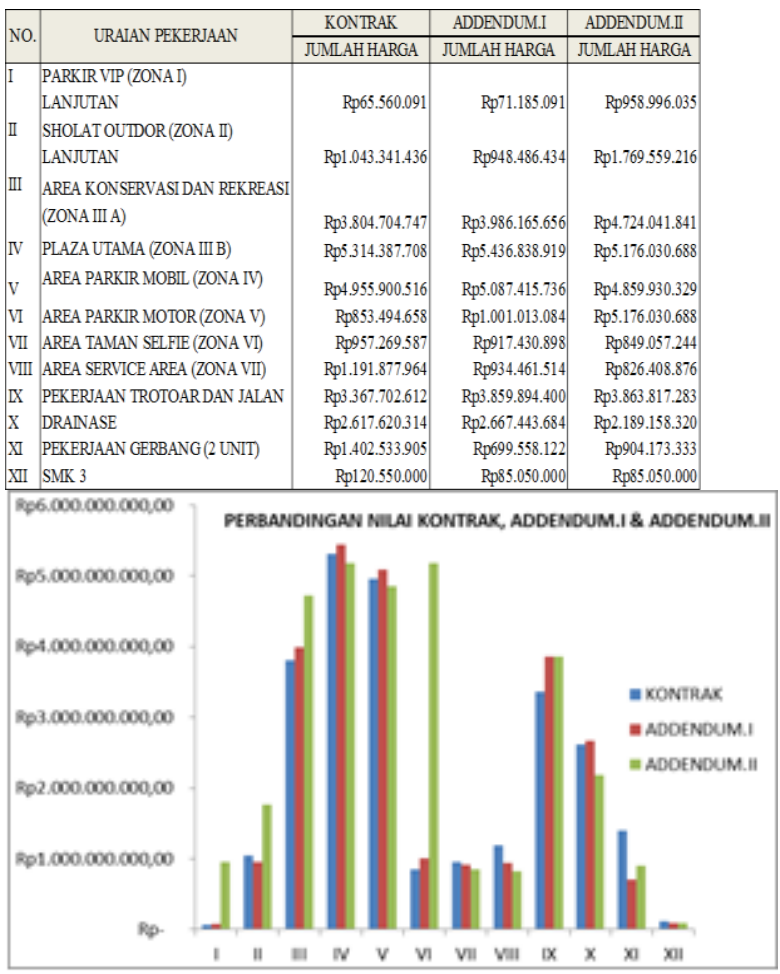

Gambar 4.1 Perbandingan antaraRekap RAB kontrak , RAB Addendum I dan RAB Addendum I

\section{Sumber :Data diolah sendiri}

\subsubsection{Keterlambatan Pekerjaan}

Banyak kendala dilapangan dan cukup luas zona pekerjaan ( terbagi atas 8 zona pekerjaan) Pekerjaan tidak dapat diselesaikan tepat waktu pada tangal 29 Desember 2017. Sehingga pekerjaan mengalami keterlambatan pekerjaan, berpedoman pada Peraturan Direktur Jenderal PerbendaharaanNomor Per-12/ PB/2017 tanggal 25 Agustus 2017 pihak kontraktor membuat surat kesanggupan penyelesaian pekerjaan dalam hal ini kontrak harus menyelesaikan pekerjaan. Kontraktor menyelesaikan pekerjaan selama 4hari.

Berdasarkan pada peraturan Peraturan Permen PUPR Nomor 31/PRT/M/2015 Lampiran I Standar dan Pedoman Pengadaan Pekerjaan Konstruksi Tunggal SSUK Pasal 66.4 huruf c menjadi pedoman pembayaran denda pekerjaan tersebut yaitu :

1. Terhadap setiap hari keterlambatan penyelesaian pekerjaan penyedia akan dikenakan denda keterlambatan sebesar 1/1000 ( satu per seribu ) dari nilai kontrak atau bagian tertentu dari nilai kontrak sebelum ppn sesuai dengan syarat-syarat umum kontrak.
Perhitungan denda pekerjaan :

$$
\begin{array}{cccccc}
1 / 1000 & X & 10 / 11 x & R p 30,264,437,000 & X & 4 \\
0.004 & X & 0.9091 x & R p 30,264,437,000 & & \\
\operatorname{Rp} 110,052,498 & &
\end{array}
$$

\section{Jadwal Proyek}

Jadwal proyek Pembangunan Penataan Bangunan Kawasan Strategis Masjid Raya Sumbar Kota Padang dilaksanakan selama Hari Kerja yaitu dari tanggal 23 Mei 2017 sampai dengan 29 Desember 2017.

\section{Proses Addedum I}

Tabel 4.2 Sisa pekerjaan minggu ke-13

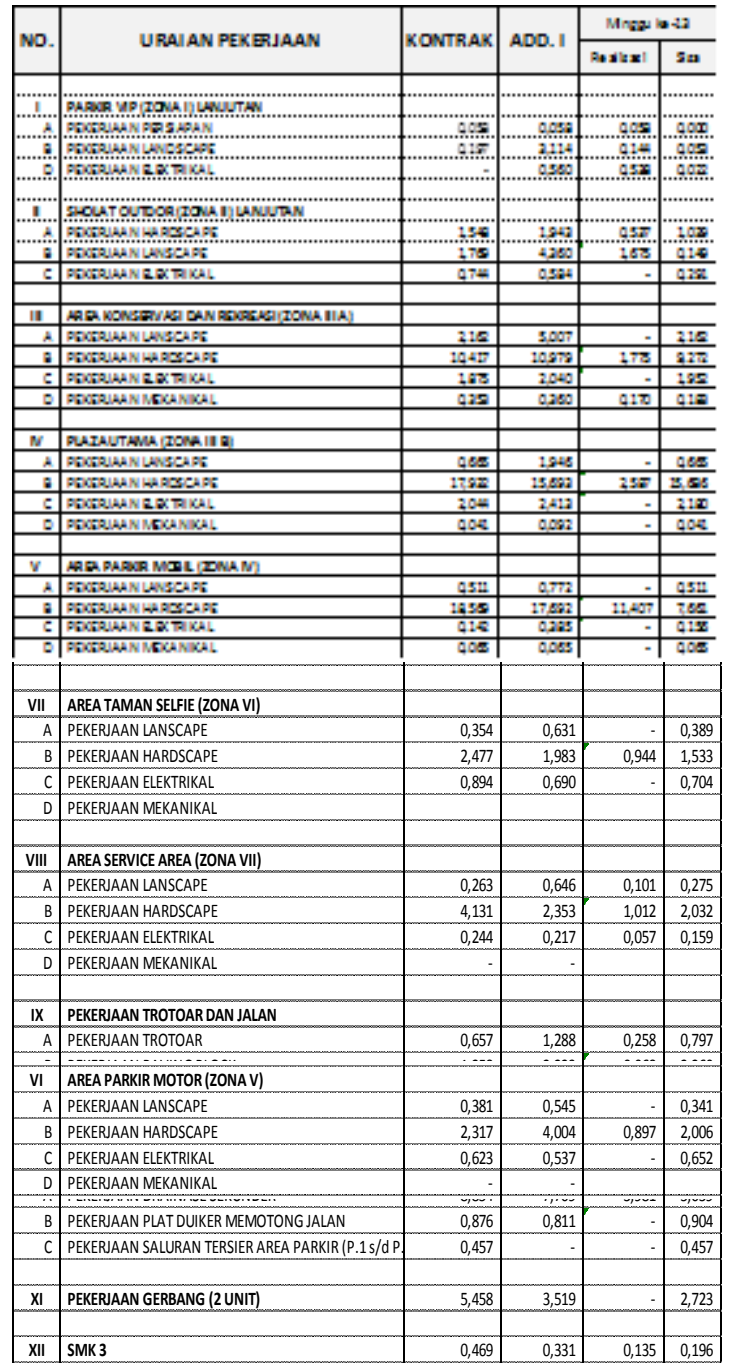




\section{- Proses Addedum II}

Tabel 4.3 Penambahan dana pada addendum II

\begin{tabular}{|c|c|c|c|c|}
\hline \multicolumn{2}{|c|}{ Sebesar } & $\mathrm{Rp}$ & \multicolumn{2}{|c|}{2.000 .000 .000} \\
\hline No. & \multicolumn{2}{|c|}{ URAIAN PEKERJAAN } & $\begin{array}{l}\text { PEKERJAAN } \\
\text { TAMBAH } \\
\end{array}$ & $\begin{array}{c}\text { ADDENDUM - II } \\
\text { JUMLAH HARGA } \\
\text { (Rp.) }\end{array}$ \\
\hline 1 & & 2 & 3 & 4 \\
\hline 1 & \multicolumn{2}{|c|}{ PARKIR VIP (ZONA I) LANJUTAN } & $1.846 .900,00$ & $958.996 .034,58$ \\
\hline II & \multicolumn{2}{|c|}{ SHOLAT OUTDOR (ZONA II) LANJUTAN } & $3.398 .543,25$ & $1.769 .559 .215,59$ \\
\hline IIII & \multicolumn{2}{|c|}{ AREA KONSERVASI DAN REKREASI (ZONA III A) } & $96.503 .920,00$ & $4.724 .041 .841,31$ \\
\hline IV & \multicolumn{2}{|c|}{ PLAZA UTAMA (ZONA III B) } & $1.129 .851 .973,17$ & 5.176.030.688,17 \\
\hline $\mathrm{v}$ & \multicolumn{2}{|c|}{ AREA PARKIR MOBIL (ZONA IV) } & & $4.859 .930 .329,00$ \\
\hline VI & \multicolumn{2}{|c|}{ AREA PARKIR MOTOR (ZONA V) } & $70.101 .900,00$ & 1.306.902.191,19 \\
\hline VIII & \multicolumn{2}{|c|}{ AREA TAMAN SELFIE (ZONA VI) } & $142.116 .961,50$ & $849.057 .243,79$ \\
\hline VIII & \multicolumn{2}{|c|}{ AREA SERVICE AREA (ZONA VII) } & 73.661.244,37 & $826.408 .875,71$ \\
\hline IX & \multicolumn{2}{|c|}{ PEKERJAAN TROTOAR DAN JALAN } & $105.264 .389,30$ & 3.863.817.283,19 \\
\hline $\mathrm{x}$ & \multicolumn{2}{|c|}{ DRAINASE } & $384.892 .622,98$ & $2.189 .158 .319,72$ \\
\hline $\mathrm{XI}$ & \multicolumn{2}{|c|}{ PEKERJAAN GERBANG (2 UNIT) } & & $904.173 .333,12$ \\
\hline \multirow[t]{6}{*}{ XII } & SMK 3 & & & $85.050 .000,00$ \\
\hline & & & & \\
\hline & \multicolumn{2}{|c|}{ TOTAL BIA } & $2.000 .000 .000,000$ & $27.513 .125 .355,37$ \\
\hline & \multirow{2}{*}{\multicolumn{2}{|c|}{ PPN $10 \%$}} & & $2.751 .312 .535,54$ \\
\hline & \multirow{2}{*}{\multicolumn{2}{|c|}{\begin{tabular}{|l|l} 
JIBLALATK \\
DIBUATK
\end{tabular}}} & & $30.264 .437 .890,91$ \\
\hline & & & & $30.264 .437 .000,00$ \\
\hline
\end{tabular}

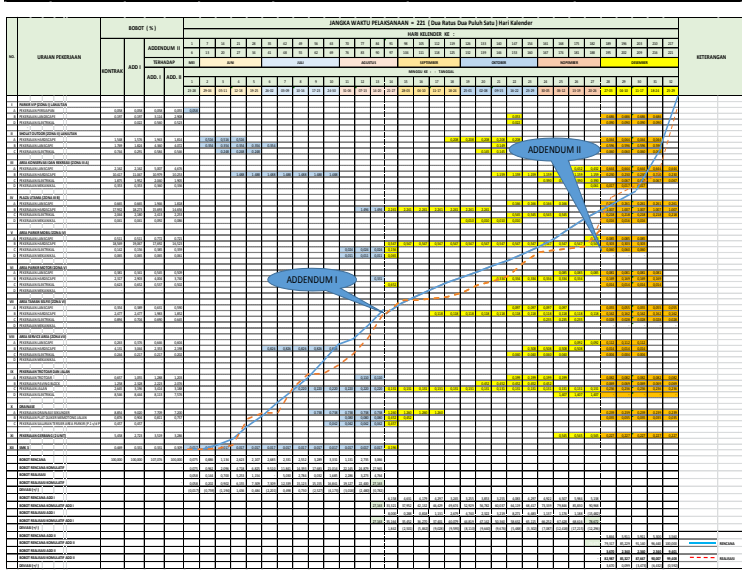

Gambar 4.4 Schedule addendum.

Berdasarkan Kurva S diatas, dapat kita bandingkan antara rencana dan realisasi bahwa :

1. Terjadi keterlambatan pada minggu ke-1 sampai minggu ke-6Pada minggu ini terjadi keterlambatan Pada item pekerjaan pondasi tangga utama dalam pekerjaan galian mengalami kendala karna pada saat pengerjaan galian ada bekas pondasi tiang pancang masjid.

2. Terjadi keterlambatan pada minggu ke-7 sampai minggu ke-13. Pada minggu ini terjadi keterlambatan pekerjaan karna adanya penentuan tapak pondasi dari Bangunan Menara Masjid dan Pembangunan Gedung Bundo Kandung yang mengangu Pekerjan Hardscape ZonaVII dan Zona IV yang sedang melakukan Review Desain.

3. Terjadi keterlambatan pada minggu ke-16 sampai minggu ke-24 Pada minggu ini terjadi Pekerjaan yang terlambat sangat signifikan sebesar terlihat pada pekerjaan drainase karna curah hujan yang saat tinggi mengakibat kan pengengerjaan mengcor drainase terhambat karna debit air dilapangan besar.

4. Terjadi keterlambatan pada minggu ke-25 sampai minggu ke-27

Pada minggu ini kembali terjadi keterlambatan. Adapun faktor yang menyebabkan keterlambatan adalah :

- Adanya perubahan desain pekerjaan atau contrack change order $(\mathrm{CCO})$

- Adanya Penambahan dana pekerjaan .

\subsection{PenjadwalanCPM (Critical Path Methode)}

Dari penjadwalan tersebut selanjutnya dianalisis menggunakan bantuan metode CPM pekerjaan selanjutnya ditabelkan sebagai berikut:

\section{a. Perhitungan waktu (Float)}

Jenis-jenis waktu (Float) dalam PCM :

1. Total Float (TF)

Adalah berapa lama suatu kegiatan boeh terlambat tanpa memperngaruhi waktu penyelesaian proyek.

2. Free Float (FF)

Adalah beberapa lama suatu boleh terlambat tanpa mempengaruhi $\mathrm{TF}$ kegiatan sebelumnya.

3. Indenpendent Float (IF)

Adalah berapa lama suatu kegiatan boleh terlambat tanpa mempengaruhi $\mathrm{TF}$ kegiatan sebelum dan sesudahnya.

4. Star Float (SF)

Adalah waktu ambang pada akhir kegiatan

\section{b. Lintasan Kritis}

Lintas kritis menandakan bahwa keenam kegiatan tersebut tidak mempunyai waktu tenggang untuk terlambat sehingga keenamnya disebut kegiatan kritis. Lintasan yang menghubungkan antar kegiatan kritis disebut lintasan kritis.Dalam penjadwalan diatas lintasan kritisnya adalah B3 - C7 - E15-F19-C6. 


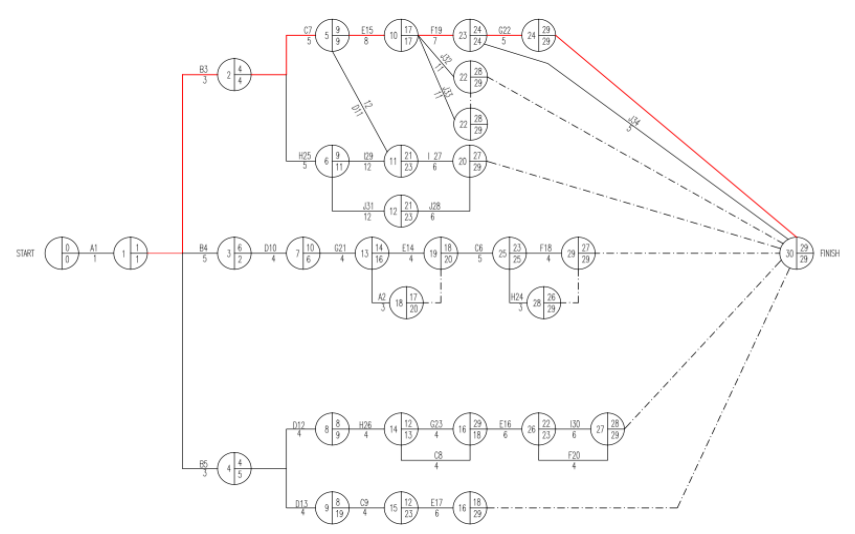

Gambar 4. 5 Gambar CPM Pekerjaan

Penataan Bangunan Kawasan strategis Masjid raya Sumbar kota Padang

\section{SIMPULAN DAN SARAN}

\subsection{Simpulan}

Berdasarkan penelitian yang telah diraiakan pada bab sebelumnya, maka penulis memberikan kesimpulan sebagai berikut:

1. RAB terkontrak tidak sesuai dengan $\mathrm{RAB}$ yang dilaksanakan Nilai Kontrak semula Rp 28,264,437,000 menjadi nilai kontrak akhir Rp 30,264,437,000dengan Addendum penambahan dana kontrak Sebesar Rp 2.000.000.000,-

2. Pembayaran pekerjaan dilakukan berdasarkan Peraturan Perbendaharaan Nomor Per-12/ PB/2017 tanggal 25 Agustus 2017 tentang Pedoman Pelaksanaan Penerimaan dan Pengeluraan Negara Pada Akhir Tahun Anggaran 2017 dengan meghitung sisa pekerjaan dilapangan. Dan berdasarkan peraturan Permen PUPR Nomor 31/PRT/M/2015 Lampiran I Standar dan Pedoman Pengadaan Pekerjaan Konstruksi Tunggal SSUK Pasal 66.4 huruf cmengancu untuk menghitung denda keterlambatan pekerjaan selama 4 hari dengan total denda pekerjaan Rp 110,052,498.

3. pekerjaan Penataan Bangunan kawasan Strategis masjid raya sumbar kota padang jumlah hari kerja sebanyak 210 hari kalender namun saat pekerjaan terlaksanakan ada terjadi addendum tambah waktu pada pekerjan tersebut sebanyak 11 hari penambahan waktu dengan total waktu pelaksanaan 221 hari kalender dan schedulle kontrak dianalisa dengan metode CPM data yang didapat 203 hari kalender kerja.

\subsection{Saran}

Berdasarkan kesimpukan diatas, maka penulis mempunyai beberapa saran sebai berikut:

1. Dalam melaksanakan proyek hendaknya mencermati faktor biaya dan waktu supaya dapat mencapai hasil yang maksimal.

2. Untuk dapat mencoba metode yang lain dalam perencanaan waktu seperti schedule barchart, serta agar lebih baik lagi dilanjutkan dengan pengendalian waktu alokasi tenaga kerja dan lembur

3. Komunikasi dan koordinasi yang baik antara pihak-pihak pengelola proyek sangat diperlukan sehingga tidak menimbulkan terjadinya hambatan pekerjaan yang berakibat pada keterlambatan pekerjaan.

\section{DAFTAR PUSTAKA}

Ervianto,Wulfarm,2004, Teori-Aplikasi Manajemen Kontruksi, Andi Yogyakarta.

Ervianto,Wulfarm I,2005Manajemen Proyek Konstruksi Edisi Revisi, Andi Yogyakarta.

Husen Abrar,2001 ,Manajemen Proyek ,Andi Yogyakarta.

Sajekti,Amien,2013,Metode Kerja Bangunan Sipil, Graha Ilmu Yogyakarta

Soeharto,Iman,1995,Manajemen Proyek dari Konseptual sampai Operasional, Erlangga Jakarta

Wahyudi, 2006, Jenis-jenis keterlambatan pada proyek, BP Panca Usaha, Jakarta 